\title{
Characterization of Switching Transients in Low Voltage Power Systems of Tea Factories in Sri Lanka
}

\author{
Earl A.R.L. Pannila, Mahesh Edirisinghe* \\ Department of Physics, University of Colombo, Colombo 03, 00300, Sri Lanka
}

Corresponding Author Email: mahesh@phys.cmb.ac.lk

https://doi.org/10.18280/ejee.224-504

Received: 20 April 2020

Accepted: 26 September 2020

\section{Keywords:}

switching transients, transient overvoltage, transient protection, surge protection, surge arresters, low voltage power systems, power quality, transient energy

\begin{abstract}
Voltage transients caused by various motors and electrical equipment of tea factories in Sri Lanka have been observed and analyzed. While reporting the major components of transients, this work extends it aspires to investigate the risk of having faults in a threephase induction motor by monitoring and analyzing the transient voltage waveforms during the starting period. Therefore, common mode transient investigations have been followed. Transient voltage signals have been obtained from high end test setup and altogether 588 waveforms have been analyzed in both the time and frequency domains. In DOL and Star-Delta starting, highest transient amplitude of $688.2 \mathrm{~V}$ and $572.1 \mathrm{~V}$ have been observed respectively. Highest transient amplitude of $976.4 \mathrm{~V}$ and $980.5 \mathrm{~V}$ were observed in DOL and Star-Delta switching respectively. Withering and rolling sections dominates over other stages, generating high amplitude transients in average, reflecting same endangerment in energy calculations as presented in voltage integral. DOL starting transients carries fast rise times as $14 \mathrm{~ns}$ and in Star-Delta it is $28 \mathrm{~ns}$. In order to assist with the exegesis of these data, transient parameters like rise time, duration, highest peak, etc.... have also been presented in statistical basis.
\end{abstract}

\section{INTRODUCTION}

Nowadays, intense technological development of electric utilities and associated power electronic gear controls is becoming increased concern about the quality of electric power. In contrary to this, they are also responsible for productivity losses due to their sensitivity to voltage disturbances including transients in a decidedly harsh environment. This mystify the scenario more, as some of electronic controls are also allies of this fortuitous power quality evils, like in variable frequency drives. In the long run, this demands great deal of screen, troubleshoot, and pre-empt power quality issues now more than ever before. The indirect effects of transient rooted damages such as increased maintenance costs, out-of-operation time in the industrial sectors due to damaged and temporary malfunctioning equipment will be much higher. As explained in the studies [1, 2], across broad consideration through many researchers in industrial power systems, the most identified and accepted consequence in starting process of motors is the voltage dip. At the same time, transient nature at the starting period of a power system has also gained great attention as they tend to make associated devices in to accelerated ageing. Whenever a load turned on or off through a switching action in the system, voltage transients possibly pierce to the specific electrical environment [3-5]. Therefore, a retrofit to equipment safety in an environmentally harsh situation can only succeed if sufficient attention is given to protecting associated electronic control gear or drivers against overvoltage conditions.

As reported in scientific literature [3, 5-14], on every occasion where the circuit conditions suddenly change, a transient is prone to be initiated, often follows with switching operations or owing to lightning. This can either be a change loading condition of the equipment or current demand predominantly. As they last only a short time and occurrence is random, it makes them little hard to capture. Consequently, a very precise measure and understanding of events occurred during disturbances are vital and can offer tremendous potential benefits for a fine analysis. A fair analysis supported by splendid measuring arrangement and capturing practices, transient disturbances will be able to investigate, understand and sometimes eliminate. Moreover, Pannila and Edirisinghe [9] and Greenwood [15] reported that sources external to the facility can give birth to transients but more commonly are grown internally. This study mainly focusing internally generated transients in tea factories located in Sri Lanka which undergoes different stages that requires machineries ranging from heavy electrical induction motors to sophisticated electronic colour separation machines. In fact, a tea factory is a place where it operates large electromechanical machineries prone to generate distressing transients while other classy electronic control elements and devices are greatly exposed to them in the same environment. It is not exaggerating to say that these internally generated frequent transients seep in to the efficiency of machines causing accelerated ageing or unplanned downtime confronting large financial loss $[9,16-$ 18]. In Insurance like financial strategic matters, currently both the insurer and the insured party concern the vulnerability of the facility due to lightning, fire like visible threats only. However due to lack of understandings of internal transient influence on the equipment, it has not yet reckoned for calculating probable loss, making misunderstandings and losses for the both parties. This study may help to fill this knowledge gap which leads to consider vulnerability due to 
internally generated transients for loss analysis.

It is important to mention that the tea manufacturing industry involves various types of machineries and equipment which used at different stages in the tea production. The machine related tea processing undergoes the standard stages, Withering, Rolling, Fermentation, Drying and Grading which uses three-phase induction motors in the capacities of $2 \mathrm{~kW}$ to $15 \mathrm{~kW}$. There are many methods in use to start three-phase induction motors such as; Direct On-Line starter (DOL), Star (Wye)-Delta starter(Y- $\Delta$ ), Auto transformer starter, Reactor or resistor starter and Soft starting $[1,2,19,20]$. During this study, it was observed that most tea factories in Sri Lanka use only first two methods of starting, depending on the power consumption of the motor.

Purpose of this study is to technically report and opening a sound awareness of transient nature in industrial site to the scientific community which possibly influence quality of power system. The influence of the electrical elements in factories, induction motors as well as capacitor banks to get VAR support on the supply system to be observed mainly. Detailing the diverse disturbances with the aftermath being sequential and disturbing the other equipment operation, such as transient bursts, high peaks, sags also expected. To analyze the impact of transient events quantitatively and qualitatively, characterizing transient parameters on a statistical basis and calculation of energy content also sought. The analysis where these transient events can be linked to possible power quality apocalypse in the facility, also planned in order to have complete power quality picture. Unveil the hidden danger of transient events and degree of nakedness of current power systems to these events which can cause even a slight detriment to the power quality, expected at the end. Reporting this, section 2 introduces the experimental setup and measurement system; section 3 introduces the methodology; section 4 elaborates results and key observations; section 5 makes a discussion and focuses on possible mitigation practices that can adopt and section 6 conclude the study mapping the objectives and findings.

\section{EXPERIMENTAL SETUP AND MEASUREMENT SYSTEM}

The block schematic of experimental setup given in Figure 1 that was used to trigger voltage transients during switching actions of various electromechanical equipment, taken at tea factories in Sri Lanka which can be categorized as Low Voltage Power Systems (LVPS). In this study, five large scaled tea factories of Sri Lanka located in Rathnapura, Nivithigala, Ayagama and Urubokka have been selected for measurements. The measurement system used in this experiment is as same as authors one of recent previous work $[9,10]$. Tektronix P6015a, 1000 times attenuated voltage probe with inner impedance of $100 \mathrm{M} \Omega$ and bandwidth of $75 \mathrm{MHz}$ was used for the measurements of voltage transients [9-12] generated by the power system due to various switching operations. Voltage waveforms were captured with PicoScope 3206A $200 \mathrm{MHz}$ oscilloscope with $500 \mathrm{Ms} / \mathrm{s}$ powered by USB port of Laptop PC (being not plugged to supply, battery-powered), in order to avoid possible interference with the power system under test. PicoScope 6 ver.6.7.40.3 used as the software for data acquisition in order to carry out transient parameter extraction and data analysis.

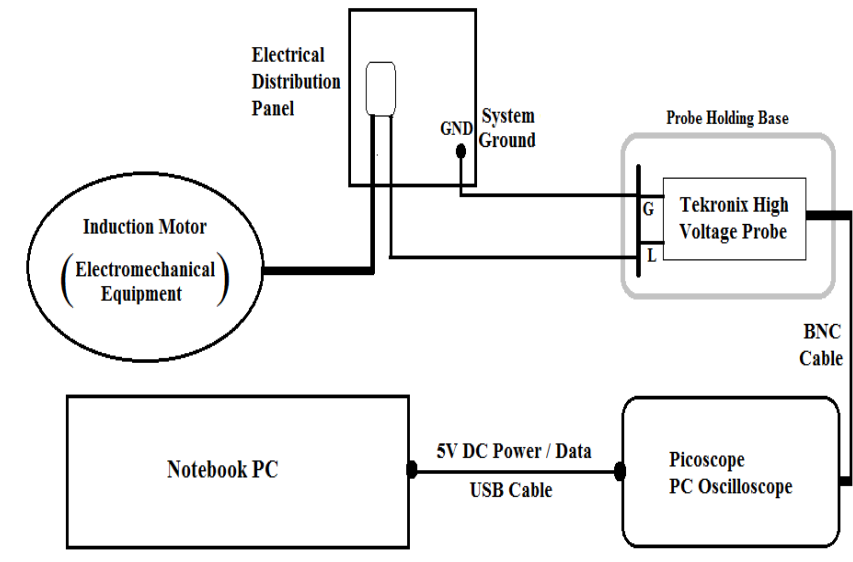

Figure 1. Transient measuring setup

\section{METHODOLOGY}

The methodology followed here is similar to what was presented in one of the early researches of authors $[9,10]$. As the study wishes to measure common mode transients of the power system in each phase, the probe linked to the $230 \mathrm{Vrms}$ system line and ground clip has been connected to the chassis of the panel which was connected to the system ground [9]. All the measured voltage transient waveforms were captured directly at the switch contact or at the distribution panel of the equipment location, as this provides a better awareness of quality of the voltage provided to the equipment and then the transient produced $[17,18]$. The 3 -core cable of $1 \mathrm{~m}$ length which brings ac supply to probe base, HV Probe's cable of 10 $\mathrm{ft}$. length and PicoScope's data and DC power cable all are laid without crossing each other guaranteeing no interference fed in any means to the data collected [9], as illustrated in Figure 2. In Figure 2, Star-Delta Electric Distribution Panel, Standard 3-core cable, Tektronix High Voltage Probe, PicoScope Oscilloscope and Notebook PC (on battery powered) are labeled as (a), (b), (c), (d) and (e) respectively. It is important to mention that in each and every possible place, it was managed to follow all the available standards and manufacturer specifications [9, 21]. Moreover, trigger threshold of the software interface was decided after measuring 5 to 10 test waveforms at each measuring attempt by observing the average noise level of the system.

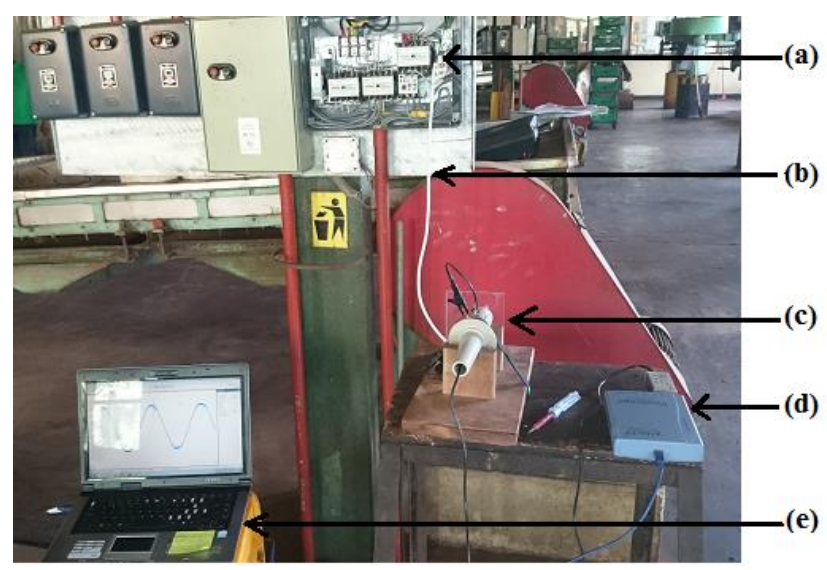

Figure 2. Depiction of test set-up 
In characterizing transient parameters, mainly two viewpoints were considered; the motor starting technique and the tea processing stage. Hence, time domain transient parameters like amplitude, rise time and pulse duration were calculated and statistically interpreted to correlate the operated electrical machine to the key attributes of transients. In this study, a collection of more than five pulses together reckoned as a burst and such burst durations were also calculated. Furthermore, for the rise time calculations, time taken to $10 \%$ to $90 \%$ of the step height considered and pulse duration of transient was also calculated.

\section{RESULTS AND OBSERVATIONS}

Five of the large scaled tea factories in Sri Lanka and its 108 different machines/locations were investigated for the analysis of its switching transient behavior and large number of switching waveforms were captured altogether. As this paper holds the dominance for common mode switching transients, only 588 waveforms which carry such significant transients were considered for the analysis and Table 1 indicates the transient observation summary.

Table 1. Transient observation summary

\begin{tabular}{|c|c|c|c|c|c|}
\hline \multicolumn{3}{|c|}{ Tea Processing Stage } & \multirow{2}{*}{$\begin{array}{l}\text { No. of } \\
\text { Factories }\end{array}$} & \multirow{2}{*}{$\begin{array}{l}\text { No. of Machines/ } \\
\text { Locations }\end{array}$} & \multirow{2}{*}{$\begin{array}{c}\text { Total Observations (No. of } \\
\text { Samples) }\end{array}$} \\
\hline $\begin{array}{l}\text { Main } \\
\text { Stage }\end{array}$ & Sub Stage & $\begin{array}{c}\text { Motor switching } \\
\text { technique }\end{array}$ & & & \\
\hline \multirow{2}{*}{\multicolumn{2}{|c|}{ Withering }} & $\overline{D O L}$ & 5 & 14 & 102 \\
\hline & & $Y-\Delta$ & 5 & 21 & 136 \\
\hline \multirow{2}{*}{\multicolumn{2}{|c|}{ Rolling }} & $D O L$ & 5 & 10 & 47 \\
\hline & & $Y-\Delta$ & 2 & 8 & 28 \\
\hline \multicolumn{2}{|c|}{ Drying } & $D O L$ & 3 & 5 & 38 \\
\hline \multirow{6}{*}{ Grading } & Winnower & $D O L$ & 5 & 13 & 45 \\
\hline & Conveyer & $D O L$ & 4 & 12 & 28 \\
\hline & Compressor & $D O L$ & 5 & 8 & 81 \\
\hline & $\begin{array}{c}\text { Color } \\
\text { Separator }\end{array}$ & $D O L$ & 5 & 10 & 32 \\
\hline & st Fan & $D O L$ & 4 & 7 & 51 \\
\hline & \multicolumn{3}{|c|}{ Total Observations (transients) } & 108 & 588 \\
\hline
\end{tabular}

Table 2. Factory wise classification of transient parameters

\begin{tabular}{|c|c|c|c|c|c|c|c|}
\hline Process Stage & \multicolumn{2}{|c|}{ Time domain transient parameter } & \multirow{2}{*}{$\begin{array}{c}\text { Factory } 1 \\
901.0\end{array}$} & \multirow{2}{*}{$\begin{array}{c}\text { Factory } 2 \\
832.0\end{array}$} & \multirow{2}{*}{$\begin{array}{c}\text { Factory } 3 \\
980.5\end{array}$} & \multirow{2}{*}{$\begin{array}{c}\text { Factory } 4 \\
812.5\end{array}$} & \multirow{2}{*}{$\begin{array}{c}\text { Factory } 5 \\
723.8\end{array}$} \\
\hline \multirow{7}{*}{ Withering } & \multirow{2}{*}{ Amplitude (V) } & $\operatorname{Max}$ & & & & & \\
\hline & & Avg. & 342.3 & 432.5 & 490.6 & 392.6 & 456.0 \\
\hline & \multirow{2}{*}{ Burst Duration ( $\mu s)$} & Max & 398.8 & 380.0 & 422.2 & 426.3 & 387.1 \\
\hline & & Avg. & 100.3 & 102.0 & 92.5 & 67.3 & 76.9 \\
\hline & \multirow{2}{*}{ Rise time (ns) } & Min & 96.0 & 48.0 & 14.0 & 42.0 & 54.0 \\
\hline & & $\operatorname{Max}$ & 178.0 & 228.0 & 262.0 & 352.0 & 128.0 \\
\hline & Duration (ns) & Max & 376.0 & 402.0 & 421.0 & 389.0 & 372.0 \\
\hline \multirow{4}{*}{ Rolling } & \multirow{2}{*}{ Amplitude (V) } & Max & 712.0 & 795.0 & 802.4 & 826.5 & 645.8 \\
\hline & & Avg. & 517.0 & 654.2 & 728.1 & 600.3 & 620.4 \\
\hline & \multirow{2}{*}{ Burst Duration ( $\mu s)$} & Max & 294.5 & 288.8 & 327.1 & 322.0 & 290.0 \\
\hline & & Avg. & 22.6 & 37.2 & 54.6 & 60.5 & 58.1 \\
\hline \multirow{8}{*}{ Drying } & \multirow{2}{*}{ Amplitude (V) } & $\operatorname{Max}$ & 842.1 & - & 798.7 & 835.6 & - \\
\hline & & Avg. & 456.3 & - & 423.5 & 354.4 & - \\
\hline & \multirow{2}{*}{ Burst Duration ( $\mu s)$} & Max & 243.1 & - & 212.6 & 185.0 & - \\
\hline & & Avg. & 71.3 & - & 61.4 & 69.8 & - \\
\hline & \multirow{2}{*}{ Rise time (ns) } & Min & 26.0 & - & 49.0 & 32.0 & - \\
\hline & & Max & 265.0 & - & 314.0 & 270.0 & - \\
\hline & \multirow{2}{*}{ Duration (ns) } & Min & 294.0 & - & 325.0 & 314.0 & - \\
\hline & & Max & 617.0 & - & 567.0 & 602.0 & - \\
\hline Grading & Amplitude (V) & $\operatorname{Max}$ & 696.6 & 725.1 & 783.6 & 711.0 & 707.5 \\
\hline
\end{tabular}


Table 3. Processing-stage wise transient parameters

\begin{tabular}{|c|c|c|c|c|c|c|c|}
\hline Process Stage & Time domain transient & ameter & Factory 1 & Factory 2 & Factory 3 & Factory 4 & Factory 5 \\
\hline \multirow{8}{*}{ Withering } & \multirow{2}{*}{ Amplitude (V) } & Max & 901.0 & 832.0 & 980.5 & 812.5 & 723.8 \\
\hline & & Avg. & 342.3 & 432.5 & 490.6 & 392.6 & 456.0 \\
\hline & \multirow{2}{*}{ Burst Duration $(\mu s)$} & Max & 398.8 & 380.0 & 422.2 & 426.3 & 387.1 \\
\hline & & Avg. & 100.3 & 102.0 & 92.5 & 67.3 & 76.9 \\
\hline & \multirow{2}{*}{ Rise time (ns) } & Min & 96.0 & 48.0 & 14.0 & 42.0 & 54.0 \\
\hline & & Max & 178.0 & 228.0 & 262.0 & 352.0 & 128.0 \\
\hline & \multirow{2}{*}{ Duration (ns) } & Min & 156.0 & 189.0 & 201.0 & 148.0 & 184.0 \\
\hline & & $\operatorname{Max}$ & 376.0 & 402.0 & 421.0 & 389.0 & 372.0 \\
\hline \multirow{8}{*}{ Rolling } & \multirow{2}{*}{ Amplitude (V) } & Max & 712.0 & 795.0 & 802.4 & 826.5 & 645.8 \\
\hline & & Avg. & 517.0 & 654.2 & 728.1 & 600.3 & 620.4 \\
\hline & \multirow{2}{*}{ Burst Duration $(\mu s)$} & Max & 294.5 & 288.8 & 327.1 & 322.0 & 290.0 \\
\hline & & Avg. & 22.6 & 37.2 & 54.6 & 60.5 & 58.1 \\
\hline & \multirow{2}{*}{ Rise time (ns) } & Min & 36.0 & 37.0 & 22.0 & 52.0 & 48.0 \\
\hline & & Max & 312.0 & 194.0 & 256.0 & 226.0 & 228.0 \\
\hline & \multirow{2}{*}{ Duration (ns) } & Min & 118.0 & 136.0 & 154.0 & 117.0 & 129.0 \\
\hline & & Max & 491.0 & 465.0 & 620.0 & 387.0 & 401.0 \\
\hline \multirow{8}{*}{ Drying } & \multirow{2}{*}{ Amplitude (V) } & Max & 842.1 & - & 798.7 & 835.6 & - \\
\hline & & Avg. & 456.3 & - & 423.5 & 354.4 & - \\
\hline & \multirow{2}{*}{ Burst Duration $(\mu \mathrm{s})$} & Max & 243.1 & - & 212.6 & 185.0 & - \\
\hline & & Avg. & 71.3 & - & 61.4 & 69.8 & - \\
\hline & \multirow{2}{*}{ Rise time (ns) } & Min & 26.0 & - & 49.0 & 32.0 & - \\
\hline & & Max & 265.0 & - & 314.0 & 270.0 & - \\
\hline & \multirow{2}{*}{ Duration (ns) } & Min & 294.0 & - & 325.0 & 314.0 & - \\
\hline & & Max & 617.0 & - & 567.0 & 602.0 & - \\
\hline \multirow{8}{*}{ Grading } & \multirow{2}{*}{ Amplitude (V) } & Max & 696.6 & 725.1 & 783.6 & 711.0 & 707.5 \\
\hline & & Avg. & 279.1 & 312.0 & 281.4 & 307.6 & 243.6 \\
\hline & \multirow{2}{*}{ Burst Duration $(\mu \mathrm{s})$} & Max & 416.0 & 342.4 & 408.0 & 421.4 & 311.6 \\
\hline & & Avg. & 31.6 & 41.0 & 78.4 & 92.6 & 54.1 \\
\hline & \multirow{2}{*}{ Rise time (ns) } & Min & 23.0 & 34.0 & 18.0 & 36.0 & 41.0 \\
\hline & & Max & 298.0 & 346.0 & 324.0 & 228.0 & 302.0 \\
\hline & \multirow{2}{*}{ Duration (ns) } & Min & 183.0 & 202.0 & 220.0 & 208.0 & 167.0 \\
\hline & & Max & 506.0 & 468.0 & 586.0 & 608.0 & 583.0 \\
\hline
\end{tabular}

Figure 3(a) and 3(b) depicts two switching transient waveforms captured at the distribution panel for motor switch off operation on Star-Delta $(\mathrm{Y}-\Delta)$ and Direct On Line (DOL) respectively. Figure 3(c) and 3(d) illustrate the impulse nature of the transients at its expanded time scale presented for highest peak observed for DOL motor. The results prove the switching of inductive loads causes the impulsive voltage transient generation. It is found that these impulsive transients are with spectral content of $1 \mu$ s rise and duration of $50 \mathrm{~ns}$ to $1 \mathrm{~ms}$, through analysis.

Figure 4 shows a comparison of transient waveforms for the said two starting techniques, DOL and Star-Delta, switching operations. These captured transients are then categorized based on Motor starting technique and tea processing stage extracting their transient parameters in the key components of the waveform. Figure 4 (a) and (d) illustrate the transients observed due to switch on of Star to Delta transition at delta contacts and DOL start respectively which are in impulsive nature. Figure 4 (b) and (e) shows transients in oscillatory nature followed by inductive kick captured due to switch off motor under no load and switch off of DOL respectively. Figure 4 (c) and (f) illustrate the transients observed due to switch off at main contractor and switch off DOL respectively which are in oscillatory nature.

Conventionally, what most matters for reliability of the connected elements in the environment as transient parameters are, the amplitude, duration and energy associated. For detailed characterization, rise times are also calculated, since very fast rising transients can cause the overvoltage to be nonuniformly distributed in motor or transformer windings [22].
Table 2 illustrates the extracted time domain transient parameters classified under five tea factories considered for this study, for its tea processing stages of Withering, Rolling, Drying and Grading which includes Winnower, Compressor and Color Separator operations.

Moreover, these extracted transient parameters were summarized with respect to the four processing stages and Exhaust Fan operations as given in Table 3.

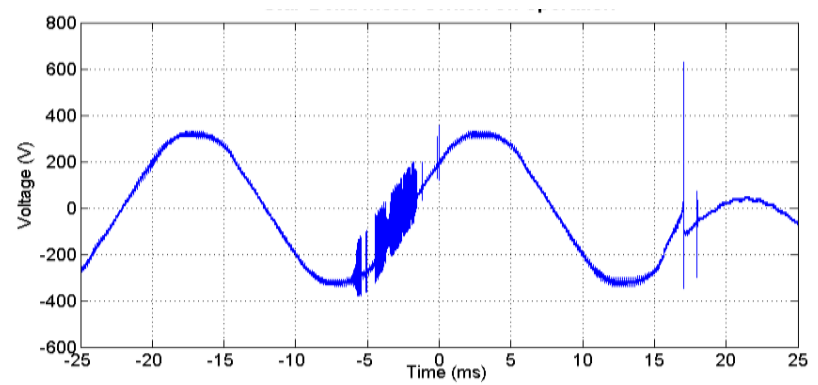

(a) at Start-Delta motor switch off operation

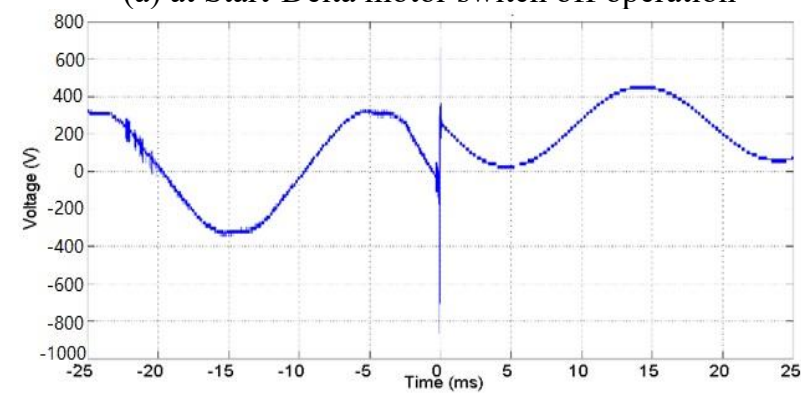

(b) at DOL motor switch off operation 


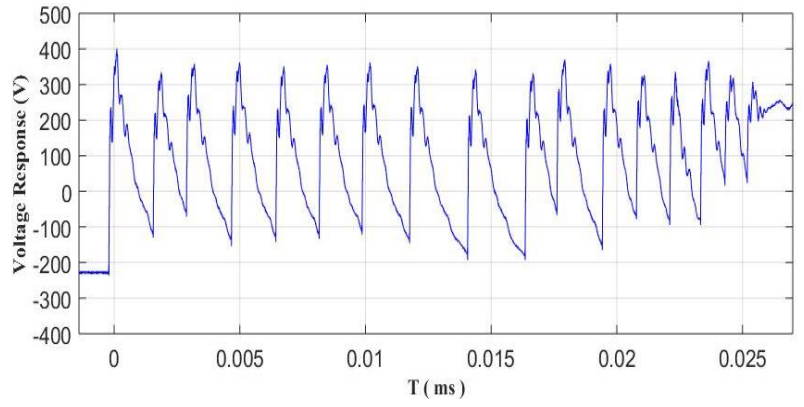

(c) at the DOL start motor switch contact

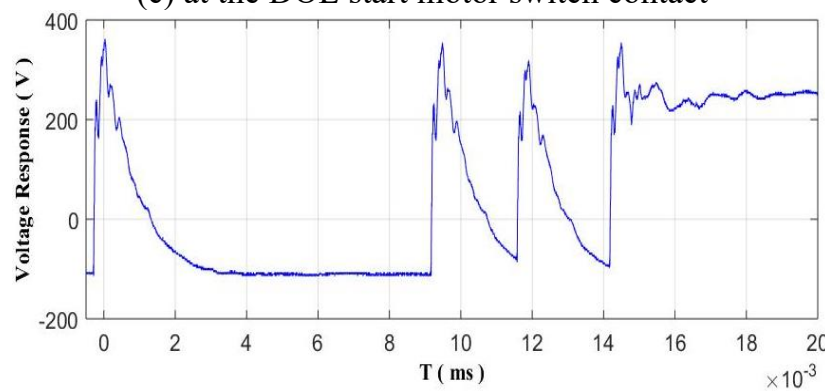

(d) at the DOL motor distribution panel

Figure 3. Star-Delta and DOL switching transients

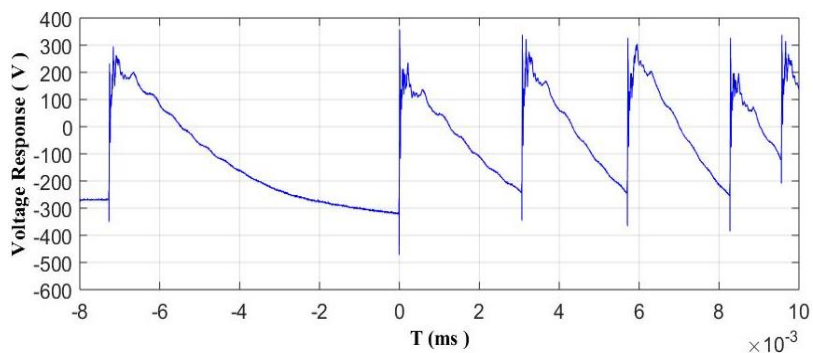

(a) Switch on, Star to Delta transition at delta contacts

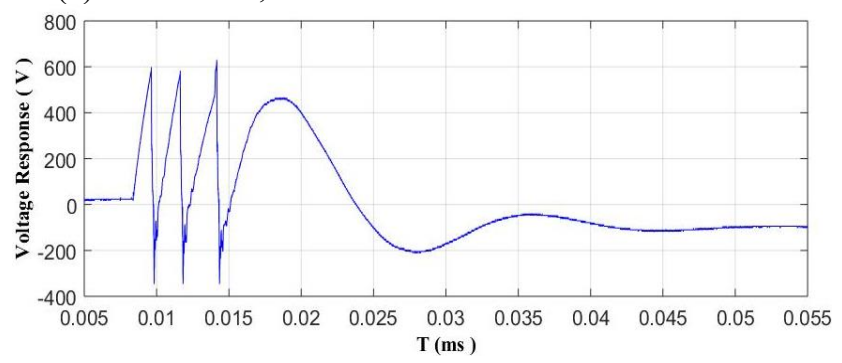

(b) switch off, motor under no load

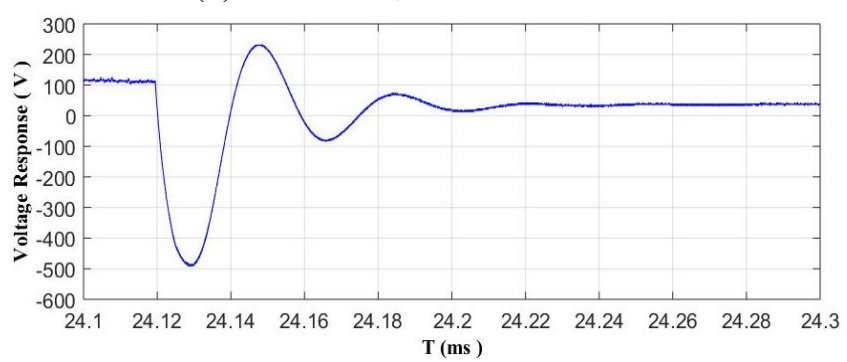

(c) switch off at main contactor

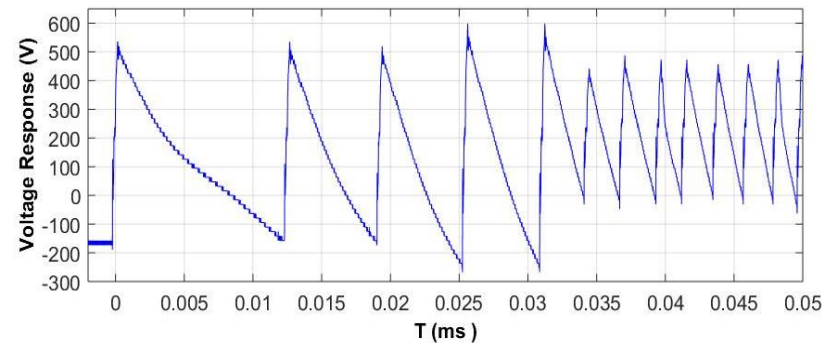

(d) Switch on DOL start

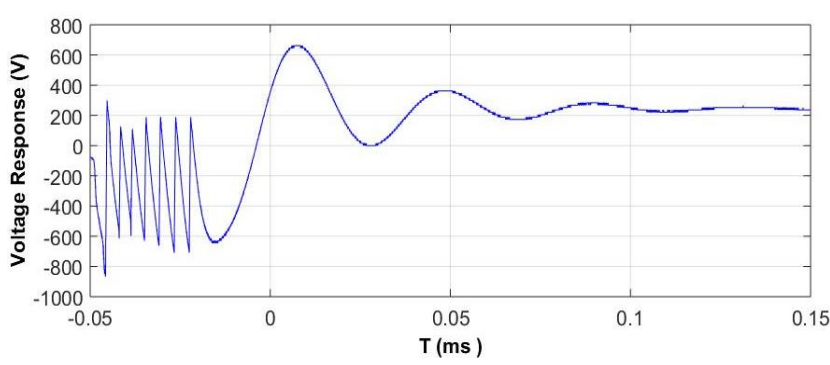

(e) Switch off, DOL

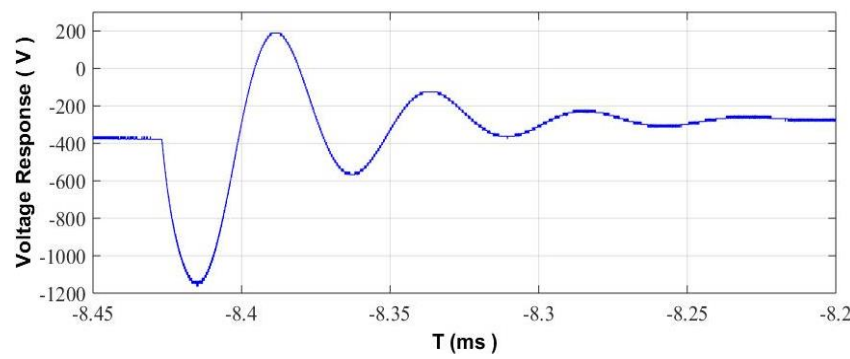

(f) switch off DOL

Figure 4. Star-Delta and DOL switching transients

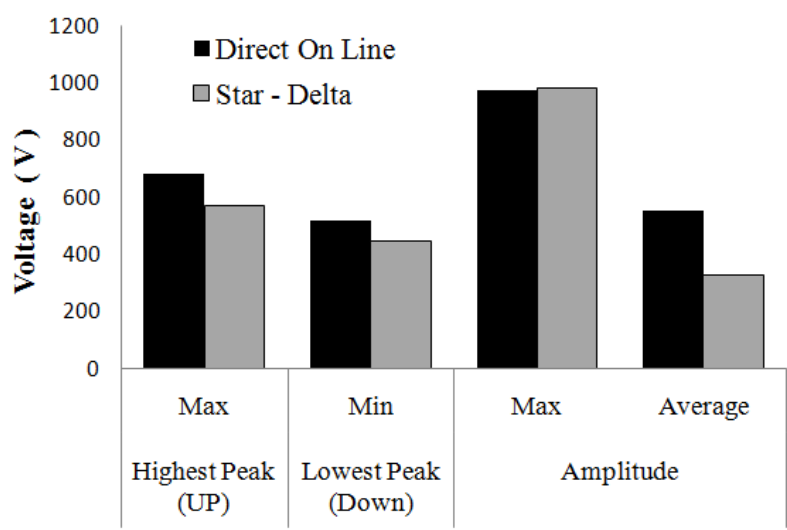

Figure 5. Transient waveforms by their positive and negative domain peak, amplitude and as averaged amplitude

Figure 5 illustrates the amplitude of transients as a comparison between DOL and Star-Delta methods for as a whole through measuring span of industry.

A previous study has been carried out for induction motors of less than $3 \mathrm{hp}$ and only severity has been commented for amplitude [1]. Looking at averages of DOL and Star-Delta transient amplitudes our results prove that transients generated by DOL starting are much severe for above $3 \mathrm{hp}$ motors also.

Figure 6 illustrates the maximum and average amplitudes measured in each manufacturing process. It is observed that withering motors tend to generate high amplitudes when the troughs are loaded. Though star-delta method tends to make transients of less amplitude in average, they generate high amplitudes in star to delta transition sometimes significantly larger as DOL starting. This is evident from Figure 5 also, as maximum amplitude of Star-Delta is higher than that of DOL but, considered in average, DOL starting dominates the transient amplitude.

As the switching happens, it is observed that switching transient occurs with highest amplitude but, most cases associated with some other repeating pulses which finally appear to be a burst in the Picoscope recording window of 50 ms. Inductive load switch-on function most cases generates an impulsive transient which sometimes damps oscillatory while 
switch-off function clearly records an oscillatory behavior. This is evident from captured waveforms in Figure 4. It is convenient to have burst duration also with amplitude information, to get some rough idea of the energy associated in a switching impulse. Burst durations are depicted in Figure 7 , at different phases as maximum and average. As a norm, a lumped appearance of more than five pulses considered as a burst.

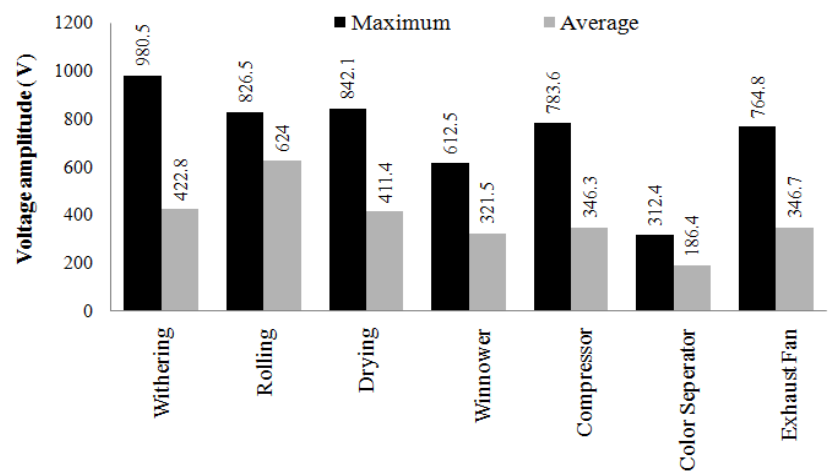

Figure 6. Transient amplitudes in average and maximum

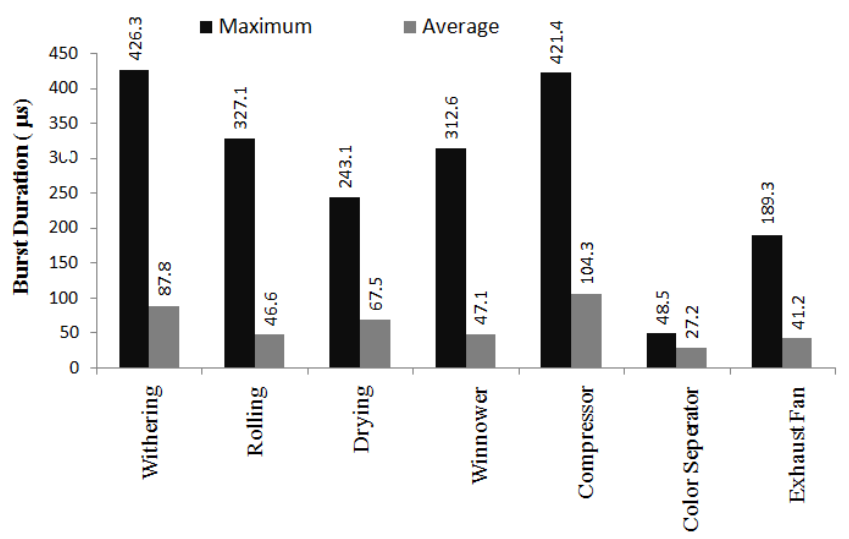

Figure 7. Burst durations of switching impulses

It is noticed that in DOL starting there appears voltage sag also with transient nature. The inrush current generates at the beginning of motor start, switching function generates the transient nature and it is observed a sag in the sinusoidal wave of voltage. When the contactors jump from Star to Delta, a similar nature was observed in Star-Delta technique also. The time in between this mechanical jump happens in magnetic contactors, which is approximately 0.25 seconds as stated in the study [1] is sufficient to establish a voltage sag in the start of motor. [5, 7]. However, it is observed at this point, a significant transient pulse also generated by contactor switching, as Figure 8. Illustrates. Though this sag is not the underlying teaser which influence the acceleration and issues regarding the torque of the motor start, nearby devices may get heavily exposed to these high amplitude, high energy transients frequently. After contactor switching, once delta connection fix, the motor acquires the stable rpm, therefore continuous measurements proved that voltage waveform become stable then after.

It can be easily compromised that, contrasting Figure 6 and Figure 7 less steep transient with higher burst-width may hold significant energy than steep and high amplitude transients with shorter presence. Several like deductions can be derived from the said two statistical figures, and that will be more intense with the numerical information with their rise times and durations. The rise time considered $10 \%$ to $90 \%$ of the step height.

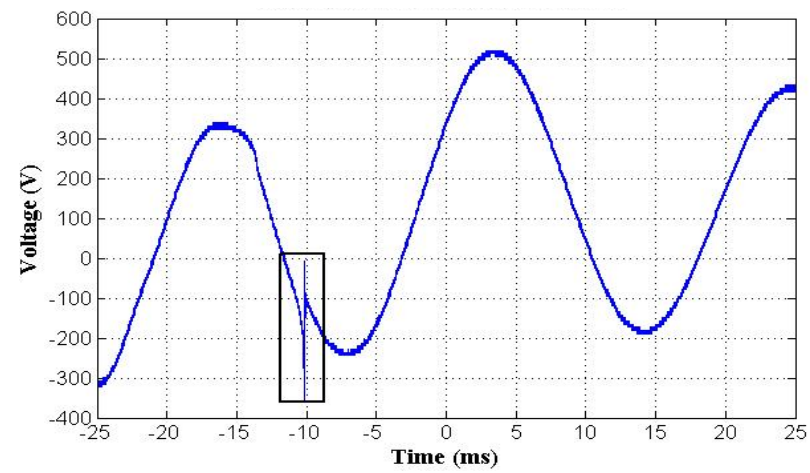

(a) DOL switching transient

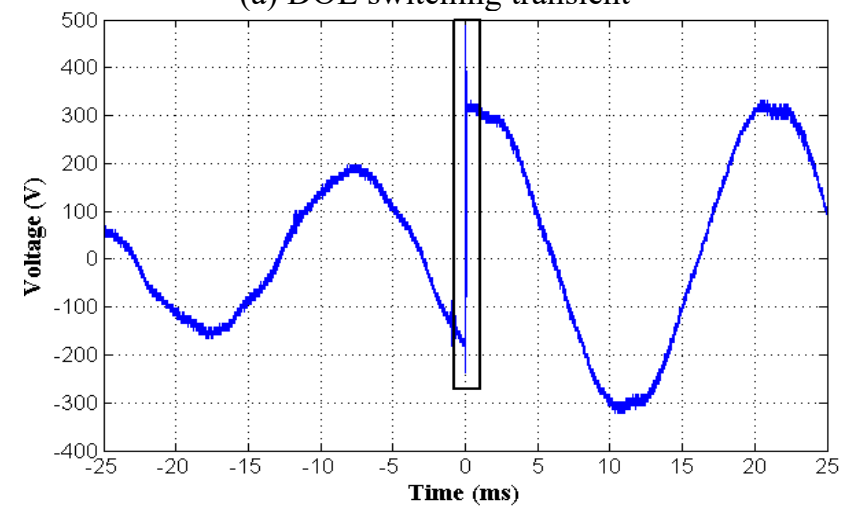

(b) Star-Delta switching transient

Figure 8. Switching transient with voltage sag

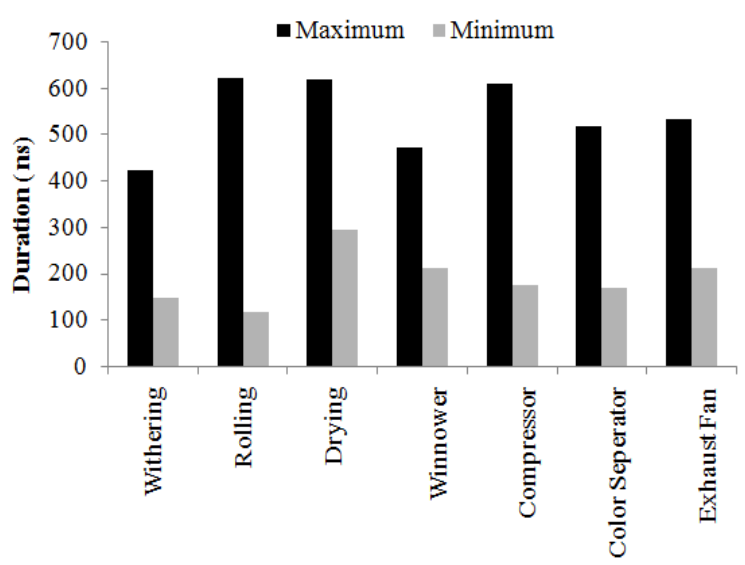

(a) Durations in maximum and minimum - Maximum Minimum

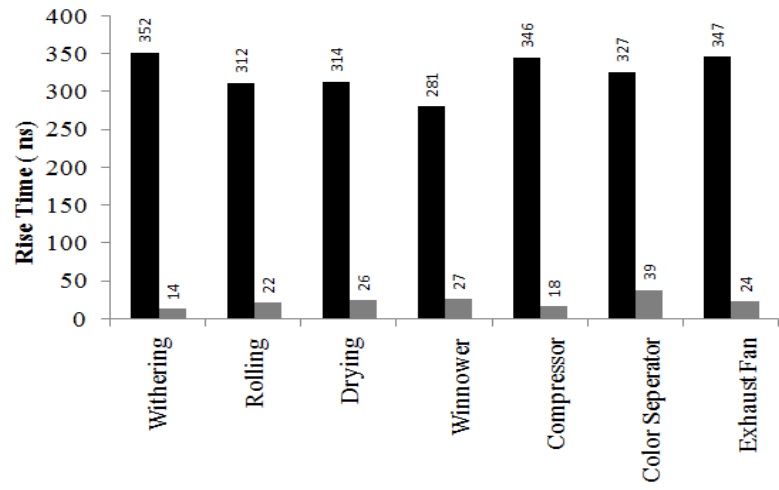

(b) Rise times maximum and minimum

Figure 9. Rise time and duration of transient pulses 

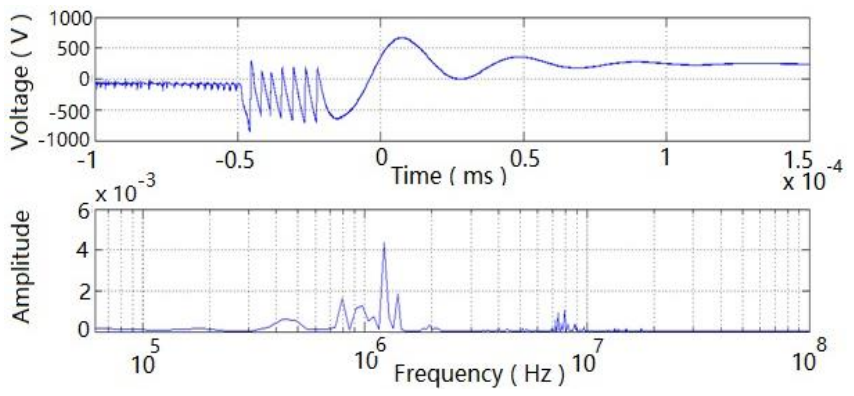

Figure 10. Frequency spectrum of transient

Table 4. Rise time (10\% - 90\%) and duration

\begin{tabular}{ccccc}
\hline & \multicolumn{2}{c}{ Rise Time } & \multicolumn{2}{c}{ Duration } \\
\hline & Min. & Max. & Min. & Max. \\
DOL & $14 \mathrm{~ns}$ & $352 \mathrm{~ns}$ & $224 \mathrm{~ns}$ & $620 \mathrm{~ns}$ \\
Y- $\Delta$ & $28 \mathrm{~ns}$ & $162 \mathrm{~ns}$ & $148 \mathrm{~ns}$ & $421 \mathrm{~ns}$ \\
\hline
\end{tabular}

The Table 4 illustrates the rise time and durations of two starting techniques in their transient nature. Figure 9 illustrates the same two transient parameters as they appear in tea processing stage. As can be seen, these low rise-times may generate high frequencies in RF range which possibly coupled with transmission and through radiation in the sensitive solidstate elements and their power electronic controls, as a result. Figure 10 depicts a transient and its respective frequency spectrum plotted.

\section{DISCUSSION}

Transient disturbances in electric power systems almost perpetual problem and there are lot of misconceptions with transient analysis in which most cases mingled with voltage sags, swells and outages. As reported in numerous surveys at diverse specific environments by previous researchers, to gain absolute and definitive knowledge in transients [3, 9, 5, 22, 23]. Some of such studies confined to certain margins like power capacity, the type of induction motors $[1,4]$ and some studies have been carried out extensively with wide view in power quality phenomenon [2,16, 19, 24-27]. Though there were few works carried out at installations and cabling [8, 9, 28, 29], no fitting pursuit in to tea factories has been done, to detect the veiled risk due to this silent killer of valuable equipment which create leeway of millions of moneys.

In most of power-quality literature, transients are mainly focused as an anomalous condition arise at the front end of power elements and steepness, amplitude and duration like single event characteristics are allocated much weight $[16,24$, $25,30]$. This is true as the transient burden do not exhibit significant and clear affliction in short time, like other major voltage interruptions. The boundaries of bad consequences of transients are limited to local environment in many cases, but intimidating consequences of this silent but devastating threat emerges more complementary studies to fill the remnants of incomplete transient definitions. At the end this always demands for rigorous and watertight argument to deduce any idea due to unpredictability of transients.

Some transient peaks of very high frequency, formed by switching actions probably surpass the recommended voltage ratings even with arresters located at the motor terminals [6] while high-duration low-amplitude transients may hit with their high energy content to the connected electrical utensils.
This is a real burden that industrial facilities have been facing as plenty of expensive electronic control devices are uncovered in a sophisticated electromechanical environment. Thus amplitude, duration, burst width, rise time and frequency are recognized as major transient parameters to report in the analysis. Even without a load the motor tends to draw greater currents across it if the motor started under Direct-On-Line scheme. In addition, these currents at starting stage typically 8 - 10 times as large as the rated current at full operation of the machine but may contain components with a wide range in frequency variation due to the change in the motor's speed. During this small age of starting transient, the machine is under the dreadful environment of severe mechanical and electrical stress. This nature is also valid for the star-delta starting even though the method controls the high starting currents, but mechanical transition switching from star to delta generates severe transients.

The energy content of a transient is rather cannot be ignored as it makes subtle instant failures to fatigues in the associated electronics. Transient caused electrical overstress analysis is a critical and important process in developing and endorsing survival of equipment in the adverse electrical environment. The waveforms captured in this survey can be considered under Electrical Fast Transients (EFTs) $[3,31]$ as the devices under test were connected to mains [3]. These transients may cause device upsets, memory losses and insulation failures at long term exposure. Not only that, in modern microelectronics, it makes a reliability concern when single event transients (SET) occurs which may be produced by exited ionizing particle which reached to tenuous semiconductor node [7, 32]. Basically, the amount of charge fed from the radiation event yields a strike of current at the junction which appears as a transient. The frequency obviously depends on the type of ion, its energy, and the properties of the configuration of the power system $[23,33]$. Therefore, it is essential component of this analysis to relate the energy content of transients in to the specific environment so as to address the suppression properly without placebos.

The readings were triggered in a setting such that root of the overvoltage is distant to the triggering point, but at the distribution Board as described in the study [9]. But as electrical installation Standards defines a separate sub circuit for each heavy inductive circuit, total energy (W) in the transient overvoltage is still of interest as a "worst-case" exposure for a protective device. The energy, $\mathrm{W}$, transferred to the load, $R_{L}$, is given by Eq. (1) [9],

$$
W=\frac{1}{R_{\text {out }}+R_{L}} \cdot \frac{R_{L}}{R_{\text {out }}+R_{L}} \cdot \int_{0}^{\infty} V^{2}(t) \cdot d t
$$

where, $\mathrm{W}$ is energy transferred to the Load

$\mathrm{R}_{\mathrm{L}}$ is Resistive Load

$\mathrm{R}_{\text {out }}$ is Output resistance of the circuit

$V(t)$ is Voltage function

The value of Energy (W) to any load $\left(\mathrm{R}_{\mathrm{L}}\right)$ can be estimated easily once the voltage integral is calculated for each case. As the computation does not account the of impedance (Z), for the consideration here, energy remains using $\mathrm{V}^{2} \mathrm{~s}$ (volts square second) as its' units. This method verified to be fair in cases where the source of the overvoltage is contiguous to the measurement point $[3,9,31]$ but calculating Energy (W) with $\mathrm{Z}-50 \Omega$ could be uses as a rough estimate of $\mathrm{W}$ in watts where $\mathrm{Z}$ is the impedance of the mains, which is function of frequency and the voltage $[9,31]$. 
Table 5. Energy generated through voltage Integral

\begin{tabular}{|c|c|c|c|c|}
\hline \multicolumn{2}{|c|}{ Tea Processing Stage (Transient Root) } & \multicolumn{3}{|c|}{ Energy by $\int V^{2} . d t\left(V^{2} s\right)$} \\
\hline Main Stage & \multirow{3}{*}{$\begin{array}{c}\text { Motor start method } \\
\text { DOL } \\
Y-\triangle\end{array}$} & \multirow{2}{*}{$\frac{\text { Maximum }}{3.16 \times 10^{4}}$} & \multirow{3}{*}{$\begin{array}{c}\text { Minimum } \\
3.12 \times 10^{3} \\
7.13 \times 10^{3}\end{array}$} & \multirow{3}{*}{$\begin{array}{c}\text { Average } \\
1.53 \times 10^{4} \\
7.66 \times 10^{3}\end{array}$} \\
\hline \multirow{2}{*}{ Witherin } & & & & \\
\hline & & $1.33 \times 10^{4}$ & & \\
\hline \multirow{2}{*}{ Rolling } & $D O L$ & $1.95 \times 10^{4}$ & $4.16 \times 10^{3}$ & $9.43 \times 10^{3}$ \\
\hline & $Y-\Delta$ & $2.72 \times 10^{4}$ & $6.91 \times 10^{3}$ & $3.84 \times 10^{3}$ \\
\hline Drying & $D O L$ & $5.12 \times 10^{4}$ & $1.01 \times 10^{4}$ & $2.89 \times 10^{4}$ \\
\hline \multirow{4}{*}{ Grading } & $D O L$ & $5.19 \times 10^{3}$ & $6.38 \times 10^{2}$ & $4.87 \times 10^{2}$ \\
\hline & $D O L$ & $2.63 \times 10^{4}$ & $4.45 \times 10^{3}$ & $8.93 \times 10^{3}$ \\
\hline & $D O L$ & $9.73 \times 10^{3}$ & $4.17 \times 10^{3}$ & $5.51 \times 10^{3}$ \\
\hline & $D O L$ & $1.45 \times 10^{3}$ & $2.46 \times 10^{2}$ & $8.13 \times 10^{2}$ \\
\hline Exhaust Fan & $D O L$ & $8.98 \times 10^{3}$ & $4.63 \times 10^{2}$ & $3.54 \times 10^{3}$ \\
\hline
\end{tabular}

Notes: 1. The Sub Stages under Grading are, a-Winnower, b- Conveyer, c- Compressor, d- Color Separator

Energy $(\mathrm{W})$ calculated (as $\int \mathrm{V}^{2}(\mathrm{t}) \cdot \mathrm{dt}$ ) is presented in Table 5 which can be used to compute power associated with a transient, in the availability of appliance's resistance and impedance of the mains at output source.

Therefore, the analysis reveals this energy content associated with voltage transients in terms of voltage integral, where that can then be easily utilized in the specific environment to calculate the real energy transferred applying circuit parameters $\left(\mathrm{R}_{\text {out }}\right.$ and $\left.\mathrm{R}_{\mathrm{L}}\right)$.

Voltage transients may present specially at places where the short circuit level of the supply is low. Such transients are addressed in the motor and wiring design but as a general resolution [34]. Many protective techniques are also available in the field for overvoltage aspects like amplitude, energy, yet the transient nature in power systems has not been particularly and precisely defined. Therefore, after proper characterization of transient phenomenon through an empirical analysis, such readily available transient suppression techniques can be adopted directly with appropriate technical supervision. Some researchers have revealed proper shielding the cables can severely mitigate and damp the current in the core letting only perturbations of low frequencies to circulate [34]. As proposed in [9] straightforward solid-state sensing arrangements can be set to trigger crowbarring mechanisms to protect sensitive electronic devices as a preparative defense. Nowadays, some of adjustable speed drives comes with these techniques inbuilt or as an option. Shunt RC snubbers, conventional series inductor arrangements or multilevel inverter mechanisms can also initially obstruct the unnecessary voltage disturbances [9]. Surge arresters of high-energy domain can use to limit the magnitude of the transient voltage at the end-user bus. Metaloxide Varistor (MOV) based Surge protective devices specially designed for industrial level equipment are also available in the field. It is important to locate them near the load and not at the breaker [6]. There are quite literatures which reveal such easy to sophisticated transient elimination procedures in the field $[3,8,15,27,35]$.

\section{CONCLUSION}

In this study, each phase is separately tapped by the measurement set-up and transients are captured at the main distribution panel. Herein, five of the large scaled tea factories of Sri Lanka have been selected for data collection and for each manufacturing stage, satisfactory amount of different machineries and number of measuring attempts were followed out in order to filter out the important transient parameters of unbalanced three-phase waveforms described.
Withering and rolling processes of most factories utilize both DOL and Star-Delta methods, depending on power capacity of motor. In DOL starting highest positive peak of $688.2 \mathrm{~V}$ and highest negative peak of $522.6 \mathrm{~V}$ was observed.

Highest amplitude of $976.4 \mathrm{~V}$ can be observed while in average it is $553.2 \mathrm{~V}$ through all measured waveforms.

Fast rises as small as $14 \mathrm{~ns}$ (in the RF frequency range $>50$ $\mathrm{MHz}$ ) and durations up to $620 \mathrm{~ns}$ are also reported from DOL motor starting.

On the other hand, Star-Delta starting highest positive peak of $572.1 \mathrm{~V}$ and highest negative peak of $448 \mathrm{~V}$ has been measured while highest and average amplitudes are $980.5 \mathrm{~V}$ and $326.8 \mathrm{~V}$ respectively.

Though highest amplitude reported in Star-Delta starting is greater than that of DOL, by observing average amplitude values it is clear that DOL starting is prone to generate considerable amount of transients with higher amplitudes.

Withering, rolling and drying sections generate more transients with higher amplitudes than other sections of the factory.

It is also observed that industrial exhaust fans being the motors having smallest power capacity, some less than $1 \mathrm{~kW}$, in this measurement criterion generate comparatively large amplitude transients. Less maintenance and stoic wiring and insulation for them being the most trivially treated equipment, cause them to generate high amplitude transients.

In the switching-burst; withering and compressor (grading) are responsible for largest bursts having burst durations 426.3 $\mu$ s and $421.4 \mu$ s respectively, while rolling and winnower motors also generate equally significant burst durations.

Use of induction motors is becoming increasingly complex and technical, use almost everywhere in niche industrial environments and sometimes making it a challenge to keep them operating at peak performance. Hence, a sound characterization of transient behavior is vital to maintain unscathed electric system and alleviate the blunders in troubleshoot. Outcomes of the research possibly be used to unfold an appropriately addressed transient mitigation practices, maintenance guide-lines, technical staff awareness, vulnerability evaluations and most importantly to generate characteristic test waveforms for future transient immunity testing.

\section{ACKNOWLEDGMENT}

The facilities provided by the Department of Physics; University of Colombo is highly appreciated. 


\section{REFERENCES}

[1] Goh, H.H., Looi, M.S., Kok, B.C. (2009). Comparison between direct-on-line, star-delta and auto-transformer induction motor starting method in terms of power quality. The International Multi Conference of Engineers and Computer Scientists, Hong Kong.

[2] Williams, A.J., Griffith, M.S. (1978). Evaluating the effects of motor starting on industrial and commercial power systems. IEEE Transactions on Industry Applications, IA-14(4): 292-305 http://doi.org/10.1109/TIA.1978.4503541

[3] Standler, R.B. (1989). Protection of Electronic Circuits from Overvoltages. John Wiley \& Sons, USA.

[4] Dillard, S.M., Greiner, T.D. (1987). Transient voltage protection for induction motors including electrical submersible pumps. IEEE Transactions on Industry Applications, $\quad$ Ia-23(2): 365-370. http://doi.org/10.1109/TIA.1987.4504914

[5] Laird, H., Round, S., Duke, R. (1998). Power quality observations at a light industrial site. 8th International Conference on Harmonics and Quality of Power Proceedings, Athens, pp. 88-93. http://doi.org/10.1109/ICHQP.1998.759845

[6] Vollet, C., Noblet, B.M. (2007). Protecting high-voltage motors against switching overvoltages. 4th European Conference on Electrical and Instrumentation Applications in the Petroleum \& Chemical Industry, Paris, pp. $1-7$. http://doi.org/10.1109/PCICEUROPE.2007.4354001

[7] Meyer, C., Schroder, S., De Doncker, R.W. (2004). Solid state circuit breakers and current limiters for mediumvoltage systems having distributed power systems. IEEE Transactions on Power Electronics, 19(5): 1333-1340. https://doi.org/10.1109/TPEL.2004.833454

[8] Sluis, L.V.D. (2001). Transients in Power Systems. John Wiley \& Sons Ltd, England.

[9] Pannila, E., Edirisinghe, M. (2014). Transients in low voltage power systems (LVPS) in Sri Lanka under modern domestic environment. IEEE 7th International Conference on Automation and Sustainability, Sri Lanka, pp. 1-6. http://doi.org/10.1109/ICIAFS.2014.7069603

[10] Pannila, E., Edirisinghe, M. (2014). Power system switching Transients in passenger automobiles. IEEE 7th International Conference on Automation and Sustainability, Sri Lanka, pp. 1-6. http://doi.org/10.1109/ICIAFS.2014.7069557

[11] Montano, R., Edirisinghe, M., Cooray, V., Roman, F. (2007). Behavior of low-voltage surge protective devices under high current derivative impulses. IEEE Transactions on Power Delivery, 22(4): 2185-2190. https://doi.org/10.1109/TPWRD.2007.905272

[12] Edirisinghe, M., Montaño, R., Cooray, V. (2004). Response of surge protection devices to fast current impulses. $27^{\text {th }}$ International Conference on Lightning Protection (ICLP), Avignon.

[13] Edirisinghe, M., Montaño, R., Cooray, V., Roman, F., (2004). Varistor models: A comparison between theory and practice. In $27^{\text {th }}$ International Conference on Lightning Protection (ICLP), Avignon, France.

[14] Edirisinghe, M., Montańo, R., Cooray, V., Roman, F. (2013). Performance comparison of varistor models under high current derivative impulses. International Letters of Chemistry, Physics and Astronomy, 6: 40-53.
https://doi.org/10.18052/www.scipress.com/ILCPA.11. 40

[15] Greenwood, A. (1991). Electrical Transients in Power Systems. 2nd ed. John Wiley \& Sons, USA.

[16] Tjäder, A., Bollen, M. (2006). Analysis of voltage transients in a medium voltage system. Nordic Distribution and Asset Management Conference, Stockholm, pp. 1-10.

[17] Michaels, K.M. (1996). Sensible approaches to diagnosing power quality problems. IAS Industrial and Commercial Power Systems Technical Conference, New Orleans, pp.

109-115. http://doi.org/10.1109/ICPS.1996.533944

[18] Michaels, K.M. (1997). Sensible approaches to diagnosing power quality problems. IEEE Transactions On Industry Applications, 33(4): 1124-1130. http://doi.org/10.1109/28.605757

[19] Cohen, V.I.V. (2000). Induction Motors - Protection and Starting. Johannesburg, South Africa.

[20] Habyarimana, M., Dorrell, D.G. (2017). Methods to reduce the starting current of an induction motor. IEEE International Conference on Power, Control, Signals and Instrumentation Engineering (ICPCSI), pp. 34-38. http://doi.org/10.1109/ICPCSI.2017.8392319

[21] British standards BS 6500:200, BS 6360:1991(BS EN 60228), BS7655:1997.

[22] Perkins, J.F. (1982). Evaluation of switching surge overvoltages on medium voltage power systems. IEEE Transactions on Power Apparatus and Systems, PAS101(6): $1727-1734$ http://doi.org/10.1109/TPAS.1982.317226

[23] Dorr, D.S., Gruzs, T.M., Hughes, M.B., Jurewicz, R.E., Dang, G., McClaine, J.L. (1996). Interpreting recent power quality surveys to define the electrical environment. IEEE Industry Applications Conference, San Diego, pp. 2251-2258. https://doi.org/10.1109/IAS.1996.563887

[24] Bollen, M.H.J., Gu, I.Y. (2007). On the analysis of voltage and current transients in three-phase power systems. IEEE Transactions On Power Delivery, 22(2): 1194-1201. http://doi.org/10.1109/TPWRD.2007.893613

[25] Nussbaumer, P., Zoeller, C., Wolbank, T.M., Vogelsberger, M.A. (2013) Transient distribution of voltages in induction machine stator windings resulting from switching of power electronics. 39th Annual Conference of the IEEE Industrial Electronics Society, Vienna pp. 3189-3194. http://doi.org/10.1109/IECON.2013.6699638

[26] Elder, S. (1992). The monitoring of induction motor starting transients with a view to early fault detection. Ph.D. Thesis. Robert Gordon University, UK.

[27] Samaras, K., Sandberg, C., Salmas, C.J., Koulaxouzidis, A. (2007). Electrical surge-protection devices for industrial facilities - a tutorial review. IEEE Transactions on Industry Applications, 43(1): 150-161. http://doi.org/10.1109/TIA.2006.886994

[28] Bollen, M.H.J., Styvaktakis, E., Gu, I.Y. (2005). Categorization and analysis of power system transients. IEEE Transactions On Power Delivery, 20(3): 22982306. http://doi.org/10.1109/TPWRD.2004.843386

[29] Johnson, W.P. (1973). Transient voltage sources and effects on electrical equipments. IEEE Transactions on Industry Applications, IA-9(3): 332-335. 
http://dx.doi.org/10.1109/TIA.1973.349912

[30] IEEE Recommended Practice for Monitoring Electric Power Quality, IEEE Standard 1159-1995, pp. 4-35.

[31] Standler, R.B. (1989). Calculation of energy in transient overvoltages. IEEE National Symposium on Electromagnetic Compatibility, pp. 217-222. http://doi.org/10.1109/NSEMC.1989.37183

[32] Ferlet-Cavrois, V., Massengill L.W., Gouker, P. (2013). Single event transients in digital CMOS - A review. IEEE Transactions on Nuclear Science, 60(6): 1767-1790. http://doi.org/10.1109/TNS.2013.2255624

[33] Black, D.A., Robinson, W.H., Wilcox, I.Z., Limbrick, D.B., Black, J.D. (2015). Modeling of single event transients with dual double-exponential current sources: Implications for logic cell characterization. IEEE Transactions on Nuclear Science, 62(4): 1540-1549. http://doi.org/10.1109/TNS.2015.2449073

[34] Dias, L., Miry, C., Guiffaut, C., Ticaud, N., Reineix, A. (2015). Calculation of lightning transient voltages in cables considering a large industrial site using a FDTD thin wire model. International Symposium on lightning Protection (XIII SIPDA), pp. 197-203. https://doi.org/10.1109/SIPDA.2015.7339312

[35] Fernandez, P., Esmeraldo, P.C.V., Carvalho, F.M.S., Camara, A., Bronzeado, H., Vaisman, R. (1998). Mitigation of power system switching transients to

improve power quality. 8th International Conference on Harmonics and Quality of Power, pp. 988-993. https://doi.org/10.1109/ICHQP.1998.760176

\section{NOMENCLATURE}

$\begin{array}{ll}\text { DOL } & \text { Direct-On-Line Starting Method } \\ \mathrm{hp} & \text { Horse Power (735.5 watts in Metric Units) } \\ \mathrm{HV} & \text { High Voltage } \\ \text { MOV } & \text { Metal Oxide Varistor } \\ \mathrm{W} & \text { Energy, J(Joules) } \\ Y-\Delta & \text { Star (Wye)-Delta Starting Method } \\ \mathrm{Z} & \text { Impedance, } \Omega\end{array}$

\section{Greek symbols}

$\Delta$

$\mu$

\section{Subscripts}

L

rms
Delta Connection of three phase supply micro (second), 10-6

Load

Root Mean Square Value of Voltage, V 